\title{
Animal Studies of Addictive Behavior
}

\author{
Louk J.M.J. Vanderschuren ${ }^{1,2}$ and Serge H. Ahmed ${ }^{3}$ \\ ${ }^{1}$ Department of Animals in Science and Society, Division of Behavioural Neuroscience, Faculty of \\ Veterinary Medicine, Utrecht University, 3584 CG Utrecht, The Netherlands \\ ${ }^{2}$ Rudolf Magnus Institute of Neuroscience, Department of Neuroscience and Pharmacology, University \\ Medical Center Utrecht, 3584 CG Utrecht, The Netherlands \\ ${ }^{3}$ Université de Bordeaux, Institut des Maladies Neurodégénératives, CNRS UMR 5293, F-33000 \\ Bordeaux, France \\ Correspondence: I.j.m.j.vanderschuren@uu.nl
}

\begin{abstract}
It is increasingly recognized that studying drug taking in laboratory animals does not equate to studying genuine addiction, characterized by loss of control over drug use. This has inspired recent work aimed at capturing genuine addiction-like behavior in animals. In this work, we summarize empirical evidence for the occurrence of several DSM-IV-like symptoms of addiction in animals after extended drug use. These symptoms include escalation of drug use, neurocognitive deficits, resistance to extinction, increased motivation for drugs, preference for drugs over nondrug rewards, and resistance to punishment. The fact that addiction-like behavior can occur and be studied in animals gives us the exciting opportunity to investigate the neural and genetic background of drug addiction, which we hope will ultimately lead to the development of more effective treatments for this devastating disorder.
\end{abstract}

$D^{\prime}$ ug addiction is an enormous medical problem, not least because of the ensuing unhealthy lifestyle and the comorbidity with other neuropsychiatric disorders. Moreover, because of its socioeconomic and legal impact on society, it affects many more people than the addicts themselves. It has been calculated that drug addiction accounts for more than $40 \%$ of the financial cost to society of all major neuropsychiatric disorders (Uhl and Grow 2004).

Addiction is a chronic relapsing disorder characterized by loss of control over drug taking. Over the course of the addiction process, drug use escalates from casual consumption to inappropriate use ("abuse"), and the subject ultimately loses control over drug seeking and taking, which is characterized by, among others, the occurrence of drug-related activities at the expense of previously important social and professional activities and continued drug use despite awareness of its adverse consequences.

Although recent years have seen progress in this regard (O'Brien 2008; Koob et al. 2009; van den Brink 2011; Pierce et al. 2012), there is still a pressing need for more effective pharmacotherapies for drug addiction, especially those that target the loss of control over drug intake which constitutes the core of the disorder. To facilitate the development of such a therapy, elucidation of the neural substrates of compulsive drug use is essential. However, the neurobiological factors that distinguish casual from compulsive drug

Editors: R. Christopher Pierce and Paul J. Kenny

Additional Perspectives on Addiction available at www.perspectivesinmedicine.org

Copyright (C) 2013 Cold Spring Harbor Laboratory Press; all rights reserved; doi: 10.1101/cshperspect.a011932

Cite this article as Cold Spring Harb Perspect Med 2013;3:a011932 
use are not known, not least because of the difficulties in establishing loss of control over drug use in animal studies. During the last two decades, several investigators have been successful in emulating the addicted phenotype in laboratory animals, and we are beginning to understand the neurobiological factors that distinguish casual from compulsive drug use (e.g., Hollander et al. 2010; Im et al. 2010; Kasanetz et al. 2010; Zapata et al. 2010).

In the present review, we will describe recent progress that has been made in studying aspects of addictive behavior in animal studies. During the last five decades, studies on drug self-administration, conditioned place preference, and intracranial self-stimulation have resulted in an enormous body of data concerning the neural substrates of drug reward and reinforcement (e.g., Wise 1996; Tzschentke 2007; O'Connor et al. 2011). This knowledge has been invaluable in our understanding of why people start using drugs, and to some extent why drug use is continued after initial exposure. However, there is increasing awareness that investigating mere drug taking in animals does not equate to studying genuine addiction, characterized by loss of control over drug use. Recognition of this fact within the field has inspired research in the last decade or two, in which researchers have attempted (and, as we wish to argue, have succeeded to a considerable degree) to capture genuine aspects of addiction-like behavior in laboratory animals (Ahmed 2005, 2012; Vanderschuren and Everitt 2005; Kenny 2007). Below, we will discuss the evidence for the occurrence of addiction-like phenotypes in animal studies. Because the DSMIV criteria for addiction (Table 1) (American Psychiatric Association 2000) are widely accepted as a touchstone to define and characterize addiction-like behavior, we will use these as a guideline to describe the animal studies. In particular, we identify several ways in which these DSM-IV criteria can be studied in an animal model (Table 2) (Wolffgramm and Heyne 1995; Ahmed and Koob 1998; Deroche-Gamonet et al. 2004; Vanderschuren and Everitt 2004; Ahmed 2012), and will then describe the evidence that these phenomena can be observed in laboratory animals after repeated or prolonged drug use.
Table 1. DSM-IV criteria for drug addiction

Pattern of drug abuse causing significant harm or suffering, as characterized by three or more of the following:

1. Tolerance

2. Withdrawal symptoms

3. Drug use in larger amounts or during longer periods than initially intended

4. Difficulty in restricting drug use

5. Great deal of time devoted to procuring and consuming drugs, and recovery from drug use

6. Important social or professional activities given up in favor of drug-related activities

7. Drug use continued despite knowledge of adverse consequences

\section{ANIMAL STUDIES OF ADDICTIVE BEHAVIOR}

\section{Escalation of Drug Use}

Escalation of drug use is a hallmark stage in the transition to addiction (Ahmed 2012). In almost all cases of addiction, the loss of control over drug use is preceded or accompanied by a dramatic increase in drug intake, which is likely to induce an array of neural adaptations that facilitate the descent into the addicted state (Vanderschuren and Everitt 2005; Kalivas and O’Brien 2008). Traditionally, increases in drug use over time have been attributed to the occurrence of tolerance (i.e., decrease in the positive or negative subjective effects of the drug) or withdrawal symptoms (whereby drug use not only serves to achieve positive subjective effects,

Table 2. Appearance of DSM-IV criteria in animal studies of drug addiction

\begin{tabular}{|c|c|}
\hline DSM-IV criterion & Behavioral equivalent \\
\hline $\begin{array}{c}\text { 1. and 2. Tolerance, } \\
\text { withdrawal }\end{array}$ & $\begin{array}{l}\text { Tolerance, escalation of } \\
\text { drug use }\end{array}$ \\
\hline $\begin{array}{l}\text { 3. Using more than } \\
\text { intended }\end{array}$ & $\begin{array}{l}\text { Impaired control, } \\
\text { neurocognitive deficits }\end{array}$ \\
\hline 4. Difficulty restricting & Resistance to extinction \\
\hline $\begin{array}{l}\text { 5. Great deal of time } \\
\text { spent }\end{array}$ & $\begin{array}{l}\text { Increased motivation for } \\
\text { drug }\end{array}$ \\
\hline $\begin{array}{l}\text { 6. Other activities given } \\
\text { up }\end{array}$ & $\begin{array}{l}\text { Drug preference over } \\
\text { nondrug rewards }\end{array}$ \\
\hline $\begin{array}{l}\text { 7. Continued use despite } \\
\text { problems }\end{array}$ & $\begin{array}{l}\text { Resistance to } \\
\text { punishment }\end{array}$ \\
\hline
\end{tabular}


but also to ameliorate the negative state of withdrawal). These two factors, that are the first two symptoms of addiction in DSM-IV, can clearly contribute to escalation of drug use. However, one should not equate escalation of drug use to tolerance because other medical, psychological, societal, and economic factors can also contribute to escalation of drug use (Ahmed 2011).

In animal studies, escalation of drug intake has been most widely investigated in cocaine and ethanol self-administration settings. In the context of cocaine self-administration, a landmark study by Ahmed and Koob (1998) showed that rats with extended access to cocaine self-administration (i.e., $6 \mathrm{~h} / \mathrm{d}$ ) gradually increased their cocaine intake across days, whereas with more limited drug access (i.e., $1 \mathrm{~h} / \mathrm{d}$ ), it remained remarkably stable, even after several months of testing (Ahmed and Koob 1999). The escalation of cocaine intake with extended access to the self-administered drug has been independently replicated many times (e.g., BenShahar et al. 2008; Mantsch et al. 2008; Oleson and Roberts 2009; Quadros and Miczek 2009; Hao et al. 2010; Hollander et al. 2010; Pacchioni et al. 2011; for review, see Ahmed 2011, 2012). Rats with a history of escalated cocaine selfadministration have also been shown to display other behavioral characteristics of addictive behavior, such as increased motivation for the drug (Paterson and Markou 2003; Lenoir and Ahmed 2008; Wee et al. 2008; Orio et al. 2009; but see Liu et al. 2005a), an increased sensitivity for reinstatement of cocaine seeking after extinction (Mantsch et al. 2004; Ahmed and Cador 2006; Kippin et al. 2006; Knackstedt and Kalivas 2007), and reduced sensitivity to punishment of cocaine seeking (Vanderschuren and Everitt 2004; Ahmed 2012). Escalation of selfadministration after extended access to the selfadministered drug has subsequently also been found for other drugs of abuse, including methamphetamine (e.g., Kitamura et al. 2006), heroin (Ahmed et al. 2000), and methylphenidate (Marusich et al. 2010), but, remarkably, not for nicotine (Paterson and Markou 2004; Kenny and Markou 2005).

In a somewhat different setting, it has been repeatedly shown that oral ethanol ingestion in rats and mice also increases over time. In a pioneering study, Wise (1973) showed that rats that received intermittent access to ethanol (i.e., every other day) gradually increased their alcohol intake over time. Subsequently, Wolffgramm and Heyne (Wolffgramm 1991; Wolffgramm and Heyne 1991, 1995) showed that after several months of relatively stable ethanol intake, rats increase their levels of ethanol drinking, which was associated with other signs of addictionlike behavior (e.g., resistance to punishment, see below). Interestingly, they showed a comparable increase over time of oral drug ingestion for other drugs, such as amphetamine (Heyne and Wolffgramm 1998), the opiate etonitazene (Wolffgramm and Heyne 1995, 1996), but less so for nicotine (Galli and Wolffgramm 2011). Consistent with these findings, Spanagel and Hölter (Hölter et al. 1998; Spanagel and Hölter 1999) showed that rats with access to different concentrations of ethanol in their home cages increased their intake after long-term ethanol exposure with repeated periods of withdrawal. In addition, these animals developed a preference to drink higher ethanol concentrations, and also showed signs of reduced sensitivity to punishment. In an operant setting, repeated deprivation from ethanol was also shown to increase responding for ethanol under both fixedratio and progressive-ratio schedules, suggesting an increase in the motivation to self-administer ethanol (Rodd et al. 2003). Extending these studies to another species, Lesscher et al. (2009) have showed that in a limited access choice paradigm, in which mice had access to ethanol for $2 \mathrm{~h} / \mathrm{d}$, these animals gradually escalated their ethanol intake over 4 wk of testing.

\section{Impaired Control over Behavior: Neurocognitive Deficits}

The occurrence of neurocognitive deficits in drug addiction is well documented (Bechara 2005; Garavan and Stout 2005; Paulus 2007; Robbins et al. 2008; Chambers et al. 2009; Goldstein et al. 2009). By and large, the cognitive deficits in addiction are relatively mild, and affect a variety of functions, such as attention, working memory, memory, planning, impulse 
control, and decision-making. These deficits contribute to the addiction in several ways. For example, impaired impulse control, in the sense of difficulty to inhibit prepotent drugtaking actions or to wait for future gratification, i.e., to weigh the delayed benefits of a drug-free lifestyle against an immediate drug reward, likely plays a critical role in the maintenance of addictive behavior. In addition, cognitive deficits in the realm of attention, working memory and memory functions may limit the success of rehabilitation programs, if participants have trouble attending to, or remembering what was learned during a counseling session. Indeed, impaired decision making on a gambling task has been shown to predict the risk of relapse in alcoholics (Bowden-Jones et al. 2005), and lack of impulse control is associated with poor treatment retention in cocaine addicts (Moeller et al. 2001) and earlier relapse in alcoholics (Charney et al. 2010).

Clearly, it is difficult to discern from studies in humans whether these neurocognitive deficits are the cause or the consequence of addictive behavior, although there is some evidence to show that impulse control deficits predisposes adolescents for smoking, alcoholism, and substance abuse (Nigg et al. 2006; Audrain-McGovern et al. 2009). Interestingly, there is an emerging body of animal studies to investigate the relationship between addictive behavior and neurocognitive function. In general, these studies support both cause and consequence notions. Thus, high impulsivity in rats predicts the vulnerability to alcohol consumption, nicotine self-administration, cocaine selfadministration, and signs of cocaine addiction (Poulos et al. 1995; Perry et al. 2005; Dalley et al. 2007a; Belin et al. 2008; Diergaarde et al. 2008), although impulsive behavior does not appear to predict heroin self-administration (McNamara et al. 2010; Schippers et al. 2012). Conversely, a period of self-administration of cocaine, methamphetamine, MDMA, or heroin has been shown to affect a variety of cognitive functions in rats, including attention, working memory, cognitive flexibility, object recognition memory, and impulsive behavior (Dalley et al. 2005, 2007b; Calu et al. 2007; Briand et al. 2008; Rogers et al. 2008; Gipson and Bardo 2009; Winstanley et al. 2009; Mendez et al. 2010; Parsegian et al. 2011; Schenk et al. 2011; Schippers et al. 2012). Interestingly, some of these deficits were specifically observed (or more prominently so) in animals with a history of escalated drug taking (Briand et al. 2008; George et al. 2008; Rogers et al. 2008; Gipson and Bardo 2009). A recent study in primates also showed cognitive inflexibility and working memory deficits after a lengthy history of cocaine self-administration (Porter et al. 2011). Interestingly though, opposite findings have also been reported, as a period of cocaine self-administration was shown to reduce impulsivity in high-impulsive rats and to improve learning and memory in a water maze (Dalley et al. 2007b; del Olmo et al. 2007), a paradoxical effect that may explain certain forms of drug self-medication.

\section{Resistance to Extinction}

Difficulty abstaining from drugs can be studied in laboratory animals by assessing drug seeking when the drug is no longer available (i.e., responding in extinction). Indeed, resistance to extinction has been observed in heroin-withdrawn rats with a history of extended access to heroin self-administration (Ahmed et al. 2000; Lenoir and Ahmed 2007; Doherty et al. 2009). However, escalation of self-administration does not seem to be a prerequisite for resistance to extinction because extended access to cocaine or methamphetamine self-administration does not result in increased responding in extinction (e.g., Mantsch et al. 2004; Sorge and Stewart 2005; Kippin et al. 2006; Allen et al. 2007; Knackstedt and Kalivas 2007; Rogers et al. 2008). Interestingly though, gradual increases in responding for cocaine during periods of explicit nonavailability of the drug have been observed in subgroups of rats that also display other signs of addiction-like behavior after prolonged cocaine self-administration experience (DerocheGamonet et al. 2004; Belin et al. 2009). Furthermore, it was recently shown that lengthy training to respond for cocaine availability under a random interval schedule (that promotes the development of an associative structure of behavior 
in which operant responding is less sensitive to the value of its outcome; [Dickinson 1985]) led to persistent responding after extinction of the cocaine taking response (Zapata et al. 2010). In this study (see also Olmstead et al. 2001), responding for a cocaine taking opportunity was sensitive to extinction in animals with a short training history, consistent with the studies described above (Deroche-Gamonet et al. 2004; Belin et al. 2009), that showed that persistent responding in extinction develops with increasing cocaine self-administration experience.

Another factor that seems to determine the sensitivity to extinction is length of withdrawal from self-administration. Thus, the degree of resistance to extinction of cocaine and heroin seeking increased with the length of withdrawal from extended drug self-administration (Ferrario et al. 2005; Zhou et al. 2009). This incubation of responding for drugs with prolonged withdrawal has been extensively studied by Shaham and colleagues (Grimm et al. 2001; for reviews, see Lu et al. 2004; Pickens et al. 2011). These studies have shown that the sensitivity to extinction of operant responding for drugs, or drug-associated cues is time-dependent. With prolonged withdrawal, responding in extinction increases, peaks (depending on the self-administered drug) between 1 wk and 3 mo postwithdrawal, and declines thereafter. Although dissipation of the response-suppressing effects of acute drug withdrawal can explain some of the rises in responding in the first few days postwithdrawal, the temporal profiles of the incubation effect, and the neural adaptations involved-the majority of which is likely not associated with the response-suppressant or anhedonic properties of drug withdrawal (Lu et al. 2004; Pickens et al. 2011)—suggest that incubation of responding for drugs also involves behavioral mechanisms related to motivation for the drug, or cognitive control over behavior.

\section{Increased Motivation for Drugs}

Motivation to take drugs in animals is most often studied using a progressive ratio schedule of reinforcement, in which animals have to make an increasing number of responses for every subsequent reward (Hodos 1961; Richardson and Roberts 1996). Using this schedule, it has been reported many times that after a period of drug self-administration, the motivation of the animals for drugs can increase. Thus, animals with a history of escalated cocaine use were found to respond at higher levels than animals that had limited cocaine access (Paterson and Markou 2003; Allen et al. 2007; Larson et al. 2007; Wee et al. 2008, 2009; Orio et al. 2009; Hao et al. 2010, but see Quadros and Miczek 2009). This effect has subsequently also been found for other drugs of abuse, including methamphetamine (Wee et al. 2007) and heroin (Lenoir and Ahmed 2007). Remarkably, Roberts and colleagues also showed that a period of drug (cocaine or heroin) self-administration leads to increased break-points under a progressive ratio schedule of reinforcement (Liu et al. 2005b, 2007; Morgan et al. 2005, 2006; Ward et al. 2006), but this increase in the motivation for cocaine appeared to be more pronounced in animals with limited drug self-administration experience (Liu et al. 2005b; Morgan et al. 2006). A subsequent study from this laboratory (Oleson and Roberts 2009) showed that escalation of cocaine intake increased the motivation for cocaine at high unit doses, but reduced the rate of responding at a threshold dose of cocaine, suggesting that after a history of escalated cocaine intake, animals take more of the drug if large amounts are available, but are not willing to pay a high price for a low amount of the drug (Oleson and Roberts 2009). In contrast, escalation of heroin self-administration was shown to increase the value of the drug, as the maximum price animals were willing to pay for heroin was increased (Lenoir and Ahmed 2008). Increases in the motivation for cocaine have also been found in a subgroup of rats with prolonged cocaine self-administration experience (DerocheGamonet et al. 2004; Belin et al. 2009).

Additional evidence for increased motivation for cocaine after escalated self-administration was obtained using the operant runway procedure. In this procedure, rats with extended cocaine use ran faster than controls to reach a goal box to receive an intravenous bolus of cocaine (Ben-Shahar et al. 2008). Somewhat 
consonant with this observation, Deroche et al. (1999) previously found that the motivational properties of the drug were augmented in the animals with the long cocaine taking history, as these animals took less time to traverse a runway for cocaine reinforcement.

\section{Drug Preference over Nondrug Rewards}

As mentioned earlier, one of the core behavioral symptoms of drug addiction is a progressive neglect of alternative pleasures or interests in favor of continued drug use. As a result of drug preference, important social, occupational, or recreational activities are given up, resulting in turn in severe opportunity costs (e.g., poor education and associated long-term negative consequences). One of the most challenging obstacles facing addiction treatments is to replace this maladaptive preference for drug use by alternative nondrug activities or behaviors.

In animal studies of addiction, drug preference can be studied by giving access to other behavioral options or choices during drug access-an opportunity lacking in standard experimental settings (Ahmed 2005, 2010). In a typical choice experiment, animals face two behavioral options: responding for a drug or for a nondrug reward, generally a small piece of food (Aigner and Balster 1978). The first choice study - which was also the first study to show drug self-administration in nonhuman animals-was conducted in adult chimpanzees (one male, one female) rendered physically dependent on morphine by passive drug administration (Spragg 1940). Chimpanzees preferred morphine over a piece of fresh fruit (orange, banana) during drug withdrawal but otherwise preferred food (see also Negus 2006). Subsequent research showed that drug preference in animals was dose-dependent (e.g., Nader and Woolverton 1991; Paronis et al. 2002; Negus 2003) and surmountable by increasing the value of the alternative nondrug reinforcer (e.g., by increasing its magnitude; Nader and Woolverton 1991). Only a subgroup of animals persisted in preferring the drug despite the opportunity of making a different choice (Nader and Woolverton 1991; Lenoir et al. 2007; Cantin et al.
2010; Kerstetter et al. 2010; Augier et al. 2011; Norman et al. 2011; Perry et al. 2011; for recent reviews, Ahmed 2010, 2012).

For instance, in a recent series of experiments, rats were offered a choice between cocaine and a nondrug reward (i.e., water sweetened with saccharin or sucrose). Facing this choice, rats preferred cocaine or were indifferent when the expected value of sweet water was low but reversed their preference toward the alternative reinforcer when its value was sufficiently high. This preference shift occurred regardless of the dose of cocaine available and even following a long history of extended access to cocaine self-administration (Lenoir et al. 2007; Cantin et al. 2010). These findings are generally consistent with previous research (Carroll et al. 1989; Carroll and Lac 1993) and with recent behavioral economics studies showing that food (or sucrose) demand was more inelastic than cocaine demand (Christensen et al. 2008; Koffarnus and Woods 2011; for review, see Kearns et al. 2011). They are also congruent with a recent study showing that mice preferred drinking sucrose over direct optostimulation of midbrain dopamine neurons (Domingos et al. 2011). After extended access to cocaine self-administration, however, a subgroup of rats (i.e., roughly $15 \%-20 \%$ ) continued to prefer cocaine over the alternative option-a behavior that could not be attributed to a mere disinterest in, or aversion to, sweet water. Indeed, when sweet water was the only option available, cocaine-preferring rats drank as much and as fast as nondrug-preferring rats (Cantin et al. 2010). Most importantly, this subgroup of cocaine-preferring rats continued to take cocaine even when hungry and offered sucrose to relieve their need of calories (Cantin et al. 2010). The persistence of cocaine preference despite its opportunity costs strongly suggests loss of control and compulsive cocaine use in these rats (see also below). The subgroup of cocaine-preferring rats may thus represent the most advanced and severe stage in the transition to cocaine addiction. This conclusion was recently generalized to other food rewards (Kerstetter et al. 2010; Perry et al. 2011) and to other drugs of abuse, including heroin (M Lenoir, L Cantin, F Serre, et al., unpubl.) and nicotine 
(Le Sage 2009; Norman et al. 2011). Finally, it is consistent with other methodological approaches that have also identified subgroups of rats resistant to the suppressive effects of punishment on cocaine, amphetamine, or nicotine self-administration (Deroche-Gamonet et al. 2004; Galli and Wolffgramm 2004, 2011; Pelloux et al. 2007; Belin et al. 2008).

\section{Resistance to Punishment}

Recent years have seen a considerable amount of studies that have tried to emulate drug use continued despite knowledge of adverse consequences in an animal experiment. These studies have in common that they have used punishment setups, in which seeking or taking drugs was paired with a negative stimulus. In studies using oral ingestion of drugs (for the most part ethanol), this has been performed by adulterating the drug solution with the bitter tastant quinine. In addition, other studies have punished drug seeking or taking with post-ingestion illness using lithium chloride, or using footshocks or shock-associated stimuli (e.g., Grove and Schuster 1974; Bergman and Johanson 1981; Kearns et al. 2002).

The quinine model was first published by Wolffgramm and Heyne (Wolffgramm 1991; Wolffgramm and Heyne 1991). This study, as well as subsequent work, showed that after a lengthy period of ethanol drinking followed by a period of forced abstinence, ethanol ingestion became insensitive to the addition of quinine. That is, if quinine was added to the ethanol that was available to rats that drank ethanol for 6-9 mo before, their intake was not, or was only to a limited extent, reduced by the bitter taste of quinine. In contrast, rats with limited ethanol experience did considerably reduce their intake. Comparable insensitivity to quinine adulteration after prolonged drug intake was subsequently found for the opiate etonitazene (Wolffgramm and Heyne 1995; Heyne 1996), amphetamine (Heyne and Wolffgramm 1998; Galli and Wolffgramm 2004), and nicotine (Galli and Wolffgramm 2011). Interestingly, the latter two studies (Galli and Wolffgramm $2004,2011)$ reported that insensitivity to qui- nine adulteration developed with lengthy amphetamine and nicotine experience in a subgroup of rats only.

The quinine adulteration model was recently followed up in two separate studies (Hopf et al. 2010; Lesscher et al. 2010). Hopf et al. (2010) showed that rats that had been allowed to drink ethanol intermittently ( $3 \mathrm{~d} / \mathrm{wk})$ for $3-$ 4 mo were insensitive to the addition of quinine to ethanol when their motivation to selfadminister ethanol under a progressive ratio schedule of reinforcement was assessed. Interestingly, sensitivity to quinine was found after shorter ethanol experience ( $1.5 \mathrm{mo})$. In a home cage drinking setup, rats with intermittent ethanol experience were less sensitive to quinine than animals that had continuous ethanol access, echoing, for example, the findings of Wise (1973) that intermittent ethanol access leads to larger amounts of ethanol ingestion than continuous access. In a limited access choice paradigm, Lesscher et al. (2010) showed that mice became insensitive to quinine adulteration after only 2 wk of ethanol experience. Thus, whereas quinine addition did suppress acquisition of ethanol drinking, adding an aversive quinine concentration to ethanol failed to reduce drinking in mice with $2 \mathrm{wk}$ of ethanol experience, when this was their only source of ethanol. Remarkably, a further sign of insensitivity to quinine emerged after 6 more weeks of ethanol experience, in that mice with an ethanol drinking history of $8 \mathrm{wk}$ became indifferent to quinine, as they drank equal amounts from bottles of ethanol with and without quinine at an aversive concentration.

In a series of studies designed to assess habitual aspects of drug seeking, Dickinson and colleagues (Dickinson et al. 2002; Miles et al. 2003) tested whether devaluation of orally ingested ethanol or cocaine, by pairing its consumption with lithium chloride-induced illness, reduced responding for these drugs. Whereas the operant responding for food appeared sensitive to devaluation, responding in extinction for ethanol or cocaine was not. Remarkably, both during taste aversion conditioning with lithium and during reacquisition of responding for the drug, responding for and 
intake of the drug solution associated with lithium-induced malaise was markedly decreased (Dickinson et al. 2002; Miles et al. 2003). This shows that drug intake can be sensitive to devaluation whereas responding for the drug in extinction is not. Given that other studies, summarized above (Wolffgramm 1991; Wolffgramm and Heyne 1991, 1995; Heyne 1996, 1998; Galli and Wolffgramm 2004, 2011; Hopf et al. 2010; Lesscher et al. 2010), clearly show that intake of the drug itself can become insensitive to punishment after prolonged drug experience, it may be possible that development of inflexible drug use occurs in a staged manner. Distal drug cues or drug-related actions become insensitive to punishment before intake of the drug itself do, perhaps representing a gradual worsening of the addiction syndrome with increasing drug experience.

Consistent with this notion, it has been shown that operant responding for drugs is initially sensitive to punishment, but that this behavioral flexibility is gradually lost after prolonged drug experience (Deroche-Gamonet et al. 2004; Vanderschuren and Everitt 2004; Pelloux et al. 2007; Belin et al. 2009). In these studies, cocaine seeking in rats was punished with footshock, or assessed in the presence of a footshock-associated conditioned stimulus (CS). In animals with limited cocaine self-administration experience, the aversive CS markedly suppressed cocaine seeking. In contrast, the footshock-associated CS had no effect on cocaine seeking in rats with a prolonged cocaine self-administration history (Vanderschuren and Everitt 2004). Following punishment by footshock (rather than a footshock-associated CS), rats with extended access to cocaine resumed drug self-administration more rapidly than animals with limited cocaine access (Ahmed 2012). Likewise, punishment of cocaine seeking with footshock also markedly suppressed responding for cocaine in animals with limited drug experience, but a subgroup of animals subsequently displayed insensitivity to punishment (Pelloux et al. 2007). In keeping with these results, Deroche-Gamonet and colleagues (Deroche-Gamonet et al. 2004; Belin et al. 2009) observed that pairing intravenous delivery of cocaine with footshock dramatically suppressed cocaine in animals with limited drug experience, but that this sensitivity to punishment was lost in a subgroup of rats after lengthy cocaine experience.

Last, in a setup based on the classic "Obstruction Box," in which rats have to cross an electrified grid to reach a reward (Jenkins et al. 1926), Cooper et al. (2007) showed that increasing the shock intensity of the grid led rats with a limited cocaine self-administration history to abstain from the drug, although the intensity needed to achieve this varied between animals. Interestingly, presentation of cocaine-associated cues then evoked reinstatement of responding for those cues, but only in a subgroup of rats. Together, these data show that with sufficient drug-taking experience, drug seeking and taking can become insensitive to punishment. However, there are marked differences between drug-experienced individuals regarding the development of this resistance to adverse consequences.

\section{CONCLUDING REMARKS}

Here we have summarized empirical evidence for the occurrence of symptoms of drug addiction in animals. Based on the DSM-IV criteria for drug addiction (Table 1) (American Psychiatric Association 2000), several symptoms of addictive behavior have been shown to occur in laboratory animals, i.e., escalation of drug use, neurocognitive deficits, resistance to extinction, increased motivation for drugs, preference for drugs over nondrug rewards, and resistance to punishment. These data indicate that addictive behavior can occur and be studied in animal models, showing that the neural machinery that underlies drug seeking and taking is present and can become dysregulated in nonhuman animals as it does in humans. This gives us the exciting opportunity to study the neural and genetic background of drug addiction in animal studies. In the case of cocaine intake escalation, this research is already underway and is beginning to reveal important neurobiological insights. For instance, it has recently culminated in the breakthrough discovery of 
entirely new molecular pathways in the dorsal striatum that controls escalation of cocaine selfadministration (Hollander et al. 2010; Im et al. 2010; for a recent review, see Ahmed and Kenny 2011). We hope that this research will, in the end, lead to the development of more effective treatments for this devastating disorder.

The summary presented here also identifies several outstanding questions that need to be addressed in future research. First, it should be recognized that occurrence of one symptom of addiction in an animal model does not equate to a model of drug addiction. Clearly, DSM-IV criteria state that three or more of seven criteria need to be met (American Psychiatric Association 2000). Therefore, one important issue is to determine whether the separate expressions of addictive behavior discussed here occur together in certain individuals or under certain conditions. There is some empirical evidence to suggest that various aspects of addictive behavior indeed co-occur (e.g., Wolffgramm 1991; Deroche-Gamonet et al. 2004). For instance, escalation of cocaine use has been shown to cooccur in the same group of individuals with increased motivation, neurocognitive deficits, drug preference, or resistance to punishment (for a recent review, see Ahmed 2012). One subsequent major challenge to the field is to elucidate the circumstances that determine the cooccurrence of various aspects of addictive behavior, and the relevant underlying neural changes. Another related challenge for future research will be to determine whether all symptoms of addiction can occur in animals or whether some symptoms are specific to humans. The latter possibility will raise interesting brain evolution issues. In addition, we need to remain aware that drug addiction, even after prolonged drug exposure, only occurs in a subgroup of individuals. Therefore, it is imperative to determine the genetic, neural, and environmental factors that render an individual vulnerable to the development of addictive behavior. These include, but are certainly not limited to, preexisting temperamental features such as impulsivity (Dalley et al. 2007b; Belin et al. 2008), sex (Anker and Carroll 2011), and social status (e.g., Wolffgramm 1991; Morgan et al. 2002).
For instance, two recent independent choice studies in rats showed that cocaine preference over palatable food was about 2-3 times more frequent in females than in males, suggesting that females may be more vulnerable to cocaine addiction (Kertstetter et al. 2009; Perry et al. 2011). Last, addictive drugs come from widely variant pharmacological classes, such as psychostimulants (cocaine, amphetamine, methamphetamine), opiates (heroin), ethanol, and nicotine. Even though each of these drugs is known to be highly addictive, their relative addictive potential varies, and their reinforcing strength depends on environmental factors (e.g., Caprioli et al. 2009; Solinas et al. 2011). Therefore, we need to identify the extent to which the occurrence of addictive behavior and its underlying neural, genetic, and environmental factors hold true for addictive drugs in general, or whether they are drug specific (Badiani et al. 2011). For instance, it was recently found that escalation of cocaine self-administration did not generalize to heroin self-administration and vice versa, suggesting that drug differences do indeed matter (Lenoir et al. 2011).

Even with these unresolved issues and outstanding questions in mind, we think that the last five decades of preclinical addiction research have generated an excellent body of information, and that the recent interest in studying genuine addiction-like behavior in animal experiments has resulted in the development of a launching pad for exciting further research that will help us to better understand the nature of the addiction syndrome.

\section{ACKNOWLEDGMENTS}

L.J.M.J.V. is supported by ZonMw (the Netherlands Organisation for Health Research and Development) Grant 91207006 (awarded to L.J.M.J.V., P. Voorn, and A.B. Smit), ZonMw (the Netherlands Organisation for Health Research and Development)/National Institute on Drug Abuse (NIDA) Collaborative Grant 60-60600-97-211 (awarded to L.J.M.J.V. and R.C. Pierce). S.H.A. is supported by the French Research Council (CNRS), the National Research Agency (ANR), the University of Bor- 
L.J.M.J. Vanderschuren and S.H. Ahmed

deaux-Segalen, and the Conseil Regional d'Aquitaine (CRA).

\section{REFERENCES}

${ }^{*}$ Reference is also in this collection.

Ahmed SH. 2005 Imbalance between drug and non-drug reward availability: A major risk factor for addiction. Eur J Pharmacol 526: 9-20.

Ahmed SH. 2010. Validation crisis in animal models of drug addiction: Beyond non-disordered drug use toward drug addiction. Neurosci Biobehav Rev 35: 172-184.

Ahmed SH. 2011. Escalation of drug use. Animal models of drug addiction. Neuromethods 53: 267-292.

Ahmed SH. 2012. The science of making drug-addicted animals. Neuroscience 211: 107-125.

Ahmed SH, Cador M. 2006. Dissociation of psychomotor sensitization from compulsive cocaine consumption. Neuropsychopharmacology 31: 563-571.

Ahmed SH, Kenny PJ. 2011. Cracking the molecular code of cocaine addiction. ILAR Journal 52: 309-320.

Ahmed SH, Koob GF. 1998. Transition from moderate to excessive drug intake: Change in hedonic set point. Science 282: 298-300.

Ahmed SH, Koob GF. 1999. Long-lasting increase in the set point for cocaine self-administration after escalation in rats. Psychopharmacology 146: 303-312.

Ahmed SH, Walker JR, Koob GF. 2000. Persistent increase in the motivation to take heroin in rats with a history of drug escalation. Neuropsychopharmacology 22: 413421.

Aigner TG, Balster RL. 1978. Choice behavior in rhesus monkeys: Cocaine versus food. Science 201: 534-535.

Allen RM, Dykstra LA, Carelli RM. 2007. Continuous exposure to the competitive $\mathrm{N}$-methyl-D-aspartate receptor antagonist, LY235959, facilitates escalation of cocaine consumption in Sprague-Dawley rats. Psychopharmacology 191: 341-351.

American Psychiatric Association. 2000. Diagnostic and statistical manual of mental disorders, IV-TR ed. American Psychiatric Association, Washington, DC.

Anker JJ, Carroll ME. 2011. Females are more vulnerable to drug abuse than males: Evidence from preclinical studies and the role of ovarian hormones. Curr Top Behav Neurosci 8: 73-96.

Anker JJ, Perry JL, Gliddon LA, Carroll ME. 2009. Impulsivity predicts the escalation of cocaine self-administration in rats. Pharmacol Biochem Behav 93: 343-348.

Audrain-McGovern J, Rodriguez D, Epstein LH, Cuevas J, Rodgers K, Wileyto EP. 2009. Does delay discounting play an etiological role in smoking or is it a consequence of smoking? Drug Alcohol Depend 103: 99-106.

Augier E, Vouillac C, Ahmed SH. 2011. Diazepam promotes choice of abstinence in cocaine self-administering rats. Addict Biol doi: 10.1111/j.1369-1600.2011.00368.x.

Badiani A, Belin D, Epstein D, Calu D, Shaham Y. 2011. Opiate versus psychostimulant addiction: The differences do matter. Nat Rev Neurosci 12: 685-700.
Bechara A. 2005. Decision making, impulse control and loss of willpower to resist drugs: A neurocognitive perspective. Nat Neurosci 8: 1458-1463.

Belin D, Mar AC, Dalley JW, Robbins TW, Everitt BJ. 2008. High impulsivity predicts the switch to compulsive cocaine-taking. Science 320: 1352-1355.

Belin D, Balado E, Piazza PV, Deroche-Gamonet V. 2009. Pattern of intake and drug craving predict the development of cocaine addiction-like behavior in rats. Biol Psychiatry 65: 863-868.

Ben-Shahar O, Posthumus EJ, Waldroup SA, Ettenberg A. 2008. Heightened drug-seeking motivation following extended daily access to self-administered cocaine. Prog Neuropsychopharmacol Biol Psychiatry 32: 863-869.

Bergman J, Johanson CE. 1981. The effects of electric shock on responding maintained by cocaine in rhesus monkeys. Pharmacol Biochem Behav 14: 423-426.

Bowden-Jones H, McPhillips M, Rogers R, Hutton S, Joyce EM. 2005. Risk-taking on tests sensitive to ventromedial prefrontal cortex dysfunction in alcohol dependency: A pilot study. J Neuropsychiatry Clin Neurosci 17: 417-420.

Briand LA, Flagel SB, Garcia-Fuster MJ, Watson SJ, Akil H, Sarter M, Robinson TE. 2008. Persistent alterations in cognitive function and prefrontal dopamine $\mathrm{D} 2$ receptors following extended, but not limited, access to self-administered cocaine. Neuropsychopharmacology 33: 29692980.

Calu DJ, Stalnaker TA, Franz TM, Singh T, Shaham Y, Schoenbaum G. 2007. Withdrawal from cocaine self-administration produces long-lasting deficits in orbitofrontal-dependent reversal learning in rats. Learn Mem 14: 325-328.

Cantin L, Lenoir M, Augier E, Vanhille N, Dubreucq S, Serre F, Vouillac C, Ahmed SH. 2010. Cocaine is low on the value ladder of rats: Possible evidence for resilience to addiction. PLoS ONE 5: e11592.

Caprioli D, Celentano M, Dubla A, Lucantonio F, Nencini P, Badiani A. 2009. Ambience and drug choice: Cocaineand heroin-taking as a function of environmental context in humans and rats. Biol Psychiatry 65: 893-899.

Carroll ME, Lac ST. 1993. Autoshaping i.v. cocaine self-administration in rats: Effects of nondrug alternative reinforcers on acquisition. Psychopharmacology 110: 5-12.

Carroll ME, Lac ST, Nygaard SL. 1989. A concurrently available nondrug reinforcer prevents the acquisition or decreases the maintenance of cocaine-reinforced behavior. Psychopharmacology 97: 23-29.

Chambers CD, Garavan H, Bellgrove MA. 2009. Insights into the neural basis of response inhibition from cognitive and clinical neuroscience. Neurosci Biobehav Rev 33: 631-646.

Charney DA, Zikos E, Gill KJ. 2010. Early recovery from alcohol dependence: Factors that promote or impede abstinence. J Subst Abuse Treat 38: 42-50.

Christensen CJ, Silberberg A, Hursh SR, Huntsberry ME, Riley AL. 2008. Essential value of cocaine and food in rats: Tests of the exponential model of demand. Psychopharmacology 198: 221-229. 
Cooper A, Barnea-Ygael N, Levy D, Shaham Y, Zangen A. 2007. A conflict rat model of cue-induced relapse to cocaine seeking. Psychopharmacology 194: 117-125.

Dalley JW, Lääne K, Pena Y, Theobald DE, Everitt BJ, Robbins TW. 2005. Attentional and motivational deficits in rats withdrawn from intravenous self-administration of cocaine or heroin. Psychopharmacology 182: 579-587.

Dalley JW, Fryer TD, Brichard L, Robinson ESJ, Theobald DEH, Lääne K, Peña Y, Murphy ER, Shah Y, Probst K, et al. 2007a. Nucleus accumbens D2/3 receptors predict trait impulsivity and cocaine reinforcement. Science 315: 1267-1270.

Dalley JW, Lääne K, Theobald DE, Pena Y, Bruce CC, Huszar AC, Wojcieszek M, Everitt BJ, Robbins TW. 2007b. Enduring deficits in sustained visual attention during withdrawal of intravenous methylenedioxymethamphetamine self-administration in rats: Results from a comparative study with d-amphetamine and methamphetamine. Neuropsychopharmacology 32: 1195-1206.

del Olmo N, Higuera-Matas A, Miguéns M, García-Lecumberri C, Ambrosio E. 2007. Cocaine self-administration improves performace in a highly demanding water maze task. Psychopharmacology 195: 19-25.

Deroche V, Le Moal M, Piazza PV. 1999. Cocaine self-administration increases the incentive motivational properties of the drug in rats. Eur J Neurosci 11: 2731-2736.

Deroche-Gamonet V, Belin D, Piazza PV. 2004. Evidence for addiction-like behavior in the rat. Science 305: 10141017.

Dickinson A. 1985. Actions and habits: The development of behavioural autonomy. Phil Trans R Soc Lond B 308: 6778 .

Dickinson A, Wood N, Smith JW. 2002. Alcohol seeking by rats: action or habit? Q J Exp Psychol 55B: 331-348.

Diergaarde L, Pattij T, Poortvliet I, Hogenboom F, De Vries W, Schoffelmeer ANM, De Vries TJ. 2008. Impulsive choice and impulsive action predict vulnerability to distinct stages of nicotine seeking in rats. Biol Psychiatry 63: 301-308.

Doherty J, Ogbomnwan Y, Williams B, Frantz K. 2009. Agedependent morphine intake and cue-induced reinstatement, but not escalation in intake, by adolescent and adult male rats. Pharmacol Biochem Behav 92: 164-172.

Domingos AI, Vaynshteyn J, Voss HU, Ren X, Gradinaru V, Zang F, Deisseroth K, de Araujo IE, Friedman J. 2011. Leptin regulates the reward value of nutrient. Nat Neurosci 14: $1562-1568$.

Ferrario CR, Gorny G, Crombag HS, Li Y, Kolb B, Robinson TE. 2005. Neural and behavioral plasticity associated with the transition from controlled to escalated cocaine use. Biol Psychiatry 58: 751-759.

Galli G, Wolffgramm J. 2004. Long-term voluntary D-amphetamine consumption and behavioral predictors for subsequent $\mathrm{D}$-amphetamine addiction in rats. Drug Alcohol Depend 73: 51-60.

Galli G, Wolffgramm J. 2011. Long-term development of excessive and inflexible nicotine taking by rats, effects of a novel treatment approach. Behav Brain Res 217: 261-270.

Garavan H, Stout JC. 2005. Neurocognitive insights into substance abuse. Trends Cogn Sci 9: 195-201.
George O, Mandyam CD, Wee S, Koob GF. 2008. Extended access to cocaine self-administration produces long-lasting prefrontal cortex-dependent working memory impairments. Neuropsychopharmacology 33: 2474-2482.

Gipson CD, Bardo MT. 2009. Extended access to amphetamine self-administration increases impulsive choice in a delay discounting task in rats. Psychopharmacology 207: 391-400.

Goldstein RZ, Craig AD, Bechara A, Garavan H, Childress AR, Paulus MP, Volkow ND. 2009. The neurocircuitry of impaired insight in drug addiction. Trends Cogn Sci 13: 372-380.

Grimm JW, Hope BT, Wise RA, Shaham Y. 2001. Incubation of cocaine craving after withdrawal. Nature 412: $141-$ 142.

Grove RN, Schuster CR. 1974. Suppression of cocaine selfadministration by extinction and punishment. Pharmacol Biochem Behav 2: 199-208.

Hao Y, Martin-Fardon R, Weiss F. 2010. Behavioral and functional evidence of metabotropic glutamate receptor $2 / 3$ and metabotropic glutamate receptor 5 dysregulation in cocaine-escalated rats: Factor in the transition to dependence. Biol Psychiatry 68: 240-248.

Heyne A. 1996. The development of opiate addiction in the rat. Pharmacol Biochem Behav 53: 11-25.

Heyne A, Wolffgramm J. 1998. The development of addiction to d-amphetamine in an animal model: Same principles as for alcohol and opiate. Psychopharmacology 140: $510-518$.

Hodos W. 1961. Progressive ratio as a measure of reward strength. Science 134: 943-944.

Hollander JA, Im HI, Amelio AL, Kocerha J, Bali P, Lu Q, Willoughby D, Wahlestedt C, Conkright MD, Kenny PJ. 2010. Striatal microRNA controls cocaine intake through CREB signalling. Nature 466: 197-202.

Hölter SM, Engelmann M, Kirschke C, Liebsch G Landgraf R, Spanagel R. 1998. Long-term ethanol selfadministration with repeated ethanol deprivation episodes changes ethanol drinking pattern and increases anxiety-related behaviour during ethanol deprivation in rats. Behav Pharmacol 9: 41-48.

Hopf FW, Chang SJ, Sparta DR, Bowers MS, Bonci A. 2010. Motivation for alcohol becomes resistant to quinine adulteration after 3 to 4 months of intermittent alcohol self-administration. Alcohol Clin Exp Res 34: 1565-1573.

Im HI, Hollander JA, Bali P, Kenny PJ. 2010. MeCP2 controls BDNF expression and cocaine intake through homeostatic interactions with microRNA-212. Nat Neurosci 13: $1120-1127$.

Jenkins TN, Warner LH, Warden CJ. 1926. Standard apparatus for the study of animal motivation. J Comp Psychol 6: $361-382$.

Kalivas PW, O’Brien C. 2008. Drug addiction as a pathology of staged neuroplasticity. Neuropsychopharmacology 33: $166-180$.

Kasanetz F, Deroche-Gamonet V, Berson N, Balado E, Lafourcade M, Manzoni O, Piazza PV. 2010. Transition to addiction is associated with a persistent impairment in synaptic plasticity. Science 328: 1709-1712. 
L.J.M.J. Vanderschuren and S.H. Ahmed

Kearns DN, Weiss SJ, Panlilio LV. 2002. Conditioned suppression of behavior maintained by cocaine self-administration. Drug Alcohol Depend 65: 253-261.

Kearns DN, Gomez-Serrano MA, Tunstall BJ. 2011. A review of preclinical research demonstrating that drug and nondrug reinforcers differentially affect behavior. Curr Drug Abuse Rev 4: 261-269.

Kenny PJ. 2007. Brain reward systems and compulsive drug use. Trends Pharmacol Sci 28: 135-141.

Kenny PJ, Markou A. 2005. Nicotine self-administration acutely activates brain reward systems and induces a long-lasting increase in reward sensitivity. Neuropsychopharmacology 31: 1203-1211.

Kerstetter KA, Ballis M, Duffin-Lutgen SM, Tran J, Behrens AM, Kippin TE. 2010. Effect of sex and dose in selecting between food and cocaine, Program No. 266.6. In Neuroscience Meeting Planner. Society for Neuroscience, San Diego, CA.

Kippin TE, Fuchs RA, See RE. 2006. Contributions of prolonged contingent and noncontingent cocaine exposure to enhanced reinstatement of cocaine seeking in rats. Psychopharmacology 187: 60-67.

Kitamura O, Wee S, Specio SE, Koob GF, Pulvirenti L. 2006. Escalation of methamphetamine self-administration in rats: A dose-effect function. Psychopharmacology 186: $48-53$.

Knackstedt LA, Kalivas PW. 2007. Extended access tot cocaine self-administration enhances drug-primed reinstatement but not behavioral sensitization.J Pharmacol Exp Ther 322: 1103-1109.

Koffarnus MN, Woods JH. 2011. Individual differences in discount rate are associated with demand for self-administered cocaine, but not sucrose. Addict Biol doi: 10.1111/ j.1369-1600.2011.00361.x.

Koob GF, Lloyd GK, Mason BJ. 2009. Development of pharmacotherapies for addiction: A Rosetta Stone approach. Nat Rev Drug Disc 8: 500-515.

Larson EB, Anker JJ, Gliddon LA, Fons KS, Carroll ME. 2007. Effects of estrogen and progesterone on the escalation of cocaine self-administration in female rats during extended access. Exp Clin Psychopharmacol 15: 461-471.

Lesage MG. 2009. Toward a nonhuman model of contingency management: effects of reinforcing abstinence from nicotine self-administration in rats with an alternative nondrug reinforcer. Psychopharmacology 203: 13-22.

Lenoir M, Ahmed SH. 2007. Heroin-induced reinstatement is specific to compulsive heroin use and dissociable from heroin reward and sensitization. Neuropsychopharmacology 32: 616-624.

Lenoir M, Ahmed SH. 2008. Supply of a nondrug substitute reduces escalated heroin consumption. Neuropsychopharmacology 33: 2272-2282.

Lenoir M, Serre F, Cantin L, Ahmed SH. 2007. Intense sweetness surpasses cocaine reward. PLoS ONE 2: e698.

Lenoir M, Guillem K, Koob GF, Ahmed SH. 2011. Drug specificity in extended access cocaine and heroin selfadministration. Addict Biol doi: 10.1111/j.1369-1600. 2011.00385.x.

Lesscher HMB, Wallace MJ, Zeng L, Wang V, Deitchman JK, McMahon T, Messing RO, Newton PM. 2009. Amygdala protein kinase $\mathrm{C}$ epsilon controls alcohol consumption. Genes Brain Behav 8: 493-499.

Lesscher HMB, Van Kerkhof LWM, Vanderschuren LJMJ. 2010. Inflexible and indifferent ethanol drinking in mice. Alcohol Clin Exp Res 34: 1219-1225.

Liu Y, Roberts DCS, Morgan D. 2005a. Effects of extendedaccess self-administration and deprivation on breakpoints maintained by cocaine in rats. Psychopharmacology 179: 644-651.

Liu Y, Roberts DCS, Morgan D. 2005b. Sensitization of the reinforcing effects of self-administered cocaine in rats: Effects of dose and intravenous injection speed. Eur $J$ Neurosci 22: 195-200.

Liu Y, Morgan D, Roberts DCS. 2007. Cross-sensitization of the reinforcing effects of cocaine and amphetamine in rats. Psychopharmacology 195: 369-375.

Lu L, Grimm JW, Hope BT, Shaham Y. 2004. Incubation of cocaine craving after withdrawal: A review of preclinical data. Neuropharmacology 47 (Suppl 1): 214-226.

Mantsch JR, Yuferov V, Mathieu-Kia AM, Ho A, Kreek MJ. 2004. Effects of extended access to high versus low cocaine doses on self-administration, cocaine-induced reinstatement and brain mRNA levels in rats. Psychopharmacology 175: 26-36.

Mantsch JR, Baker DA, Francis DM, Katz ES, Hoks MA, Serge JP. 2008. Stressor- and corticotropin releasing factor-induced reinstatement and active stress-related behavioral responses are augmented following long-access cocaine self-administration by rats. Psychopharmacology 195: 591-603.

Marusich JA, Beckmann IS, Gipson CD, Bardo MT. 2010 Methylphenidate as a reinforcer in rats: Contingent delivery and intake escalation. Exp Clin Psychopharmacol 18: $257-266$.

McNamara R, Dalley JW, Robbins TW, Everitt BJ, Belin D. 2010. Trait-like impulsivity does not predict escalation of heroin self-administration in the rat. Psychopharmacology 212: $453-464$.

Mendez IA, Simon NW, Hart N, Mitchell MA, Nation JR, Wellman PJ, Setlow B. 2010. Self-administered cocaine causes long-lasting increases in impulsive choice in a delay discounting task. Behav Neurosci 124: 470-477.

Miles FJ, Everitt BJ, Dickinson A. 2003. Oral cocaine seeking by rats: Action or habit? Behav Neurosci 117: 927-938.

Moeller FG, Dougherty DM, Barratt ES, Schmitz JM, Swann AC, Grabowski J. 2001. The impact of impulsivity on cocaine use and retention in treatment. J Subst Abuse Treat 21: 193-198.

Morgan D, Grant KA, Gage HD, Mach RH, Kaplan JR, Prioleau O, Nader SH, Buchheimer N, Ehrenkaufer RL, Nader MA. 2002. Social dominance in monkeys: Dopamine D2 receptors and cocaine self-administration. Nat Neurosci 5: 169-174.

Morgan D, Smith MA, Roberts DCS. 2005. Binge self-administration and deprivation produces sensitization to the reinforcing effects of cocaine in rats. Psychopharmacology 178: 309-316.

Morgan D, Liu Y, Roberts DCS. 2006. Rapid and persistent sensitization to the reinforcing effects of cocaine. Neuropsychopharmacology 31: 121-128. 
Nader MA, Woolverton WL. 1991. Effects of increasing the magnitude of an alternative reinforcer on drug choice in a discrete-trials choice procedure. Psychopharmacology 105: 169-174.

Negus SS. 2003. Rapid assessment of choice between cocaine and food in rhesus monkeys: Effects of environmental manipulations and treatment with d-amphetamine and flupenthixol. Neuropsychopharmacology 28: 919-931.

Negus SS. 2006. Choice between heroin and food in nondependent and heroin-dependent rhesus monkeys: Effects of naloxone, buprenorphine and methadone. J Pharmacol Exp Ther 317: 711-723.

Nigg JT, Wong MM, Martel MM, Jester JM, Puttler LI, Glass JM, Adams KM, Fitzgerald HE, Zucker RA. 2006. Poor response inhibition as a predictor of problem drinking and illicit drug use in adolescents at risk for alcoholism and other substance use disorders. J Am Acad Child Adolesc Psychiatry 45: 468-475.

Norman N, Hogarth L, Panlilio L, Shoaib M. 2011. Establishing concurrent choice procedures with intravenous nicotine and sucrose in rats. In 14th EBPS Biennial Meeting. Amsterdam, The Netherlands.

O’Brien CP. 2008. Evidence-based treatments for addiction. Phil Trans R Soc Lond B 363: 3277-3286.

O’Connor EC, Chapman K, Butler P, Mead AN. 2011. The predictive validity of the rat self-administration mode for abuse liability. Neurosci Biobehav Rev 35: 912-938.

Oleson EB, Roberts DCS. 2009. Behavioral economic assessment of price and cocaine consumption following selfadministration histories that produce escalation of either final ratios or intake. Neuropsychopharmacology 34: 796-804.

Olmstead MC, Lafond MV, Everitt BJ, Dickinson A. 2001. Cocaine seeking by rats is a goal-directed action. Behav Neurosci 115: 394-402.

Orio L, Edwards S, George O, Parsons LH, Koob GF. 2009. A role for the endocannabinoid system in the increased motivation for cocaine in extended-access conditions. J Neurosci 29: 4846-4857.

Pacchioni AM, Gabriele A, See RE. 2011. Dorsal striatum mediation of cocaine-seeking after withdrawal from short or long daily access cocaine self-administration in rats. Behav Brain Res 218: 396-400.

Paronis CA, Gasior M, Bergman J. 2002. Effects of cocaine under concurrent fixed ratio schedules of food and IV drug availability: A novel choice procedure in monkeys. Psychopharmacology 163: 283-291.

Parsegian A, Glen WB Jr, Lavin A, See RE. 2011. Methamphetamine self-administration produces attentional setshifting deficits and alters prefrontal cortical neurophysiology in rats. Biol Psychiatry 69: 253-259.

Paterson NE, Markou A. 2003. Increased motivation for self-administered cocaine after escalated cocaine intake. NeuroReport 14: 2229-2232.

Paterson NE, Markou A. 2004. Prolonged nicotine dependence associated with extended access to nicotine selfadministration in rats. Psychopharmacology 173: 64-72.

Paulus MP. 2007. Decision-making dysfunctions in psychiatry—altered homeostatic processing? Science 318: $602-$ 606
Pelloux Y, Everitt BJ, Dickinson A. 2007. Compulsive drug seeking by rats under punishment: Effects of drug taking history. Psychopharmacology 194: 127-137.

Perry JL, Larson EB, German JP, Madden GJ, Carroll ME. 2005. Impulsivity (delay discounting) as a predictor of acquisition of IV cocaine self-administration in female rats. Psychopharmacology 178: 193-201.

Perry AN, Westenbroek C, Becker JB. 2011. Sex differences in the development of cocaine preferences and the loss of interest in palatable food rewards, Program No. 688.06. In Neuroscience Meeting Planner. Society for Neuroscience, San Diego, CA.

Pickens CL, Airavaara M, Théberge F, Fanous S, Hope BT, Shaham Y. 2011. Neurobiology of the incubation of drug craving. Trends Neurosci 34: 411-420.

* Pierce RC, O’Brien CP, Kenny PJ, Vanderschuren LJMJ. 2012. Rational development of addiction pharmacotherapies: Successes, failures, and prospects. Cold Spring Harb Perspect Med doi: 10.1101/cshperspect.a012880.

Porter JN, Olsen AS, Gurnsey K, Dugan BP, Jedema HP, Bradberry CW. 2011. Chronic cocaine self-administration in rhesus monkeys: Impact on associative learning, cognitive control, and working memory. J Neurosci 31: $4926-4934$.

Poulos CX, Le AD, Parker JL. 1995. Impulsivity predicts individual susceptibility to high levels of alcohol self-administration. Behav Pharmacol 6: 810-814.

Quadros IMH, Miczek KA. 2009. Two modes of intense cocaine bingeing: Increased persistence after social defeat stress and increased rate of intake due to extended access conditions in rats. Psychopharmacology 206: 109-120.

Richardson NR, Roberts DCS. 1996. Progressive ratio schedules in drug self-administration studies in rats: A method to evaluate reinforcing efficacy. J Neurosci Methods 66: $1-11$.

Robbins TW, Ersche KD, Everitt BJ. 2008. Drug addiction and the memory systems of the brain. Ann NY Acad Sci 1141: $1-21$.

Rodd ZA, Bell RL, Kuc KA, Murphy JM, Lumeng L, Li T-K, McBride WJ. 2003. Effects of repeated alcohol deprivations on operant ethanol self-administration by alcoholpreferring (P) rats. Neuropsychopharmacology 28: 16141621.

Rogers JL, De Santis S, See RE. 2008. Extended methamphetamine self-administration enhances reinstatement of drug seeking and impairs novel object recognition in rats. Psychopharmacology 199: 615-624.

Schenk S, Harper DN, Do J. 2011. Novel object recognition memory: measurement issues and effects of MDMA selfadministration following short inter-trial intervals. J Psychopharmacol 25: 1043-1052.

Schippers MC, Binnekade R, Schoffelmeer ANM, Pattij T, De Vries TJ. 2012. Unidirectional relationship between heroin self-administration and impulsive decision-making in rats. Psychopharmacology 219: 443-452.

Solinas M, Thiriet N, Chauvet C, Jaber M. 2011. Prevention and treatment of drug addiction by environmental enrichment. Prog Neurobiol 92: 572-592.

Sorge RE, Stewart J. 2005. The contribution of drug history and time since termination of drug taking to footshock 
L.J.M.J. Vanderschuren and S.H. Ahmed

stress-induced cocaine seeking in rats. Psychopharmacology 183: $210-217$.

Spanagel R, Hölter SM. 1999. Long-term alcohol self-administration with repeated alcohol deprivation phases: An animal model of alcoholism? Alcohol Alcohol 34: 231-243.

Spragg SDS. 1940. Morphine addiction in chimpanzees. Comp Psychol Monogr 15: 1-132.

Tzschentke TM. 2007. Measuring reward with the conditioned place preference (CPP) paradigm: Update of the last decade. Addict Biol 12: 227-462.

Uhl GR, Grow RW. 2004. The burden of complex genetics in brain disorders. Arch Gen Psychiatry 61: 223-229.

van den Brink W. 2011. Evidence-based pharmacological treatment of substance use disorders and pathological gambling. Curr Drug Abuse Rev 5: 3-31

Vanderschuren LJMJ, Everitt BJ. 2004. Drug seeking becomes compulsive after prolonged cocaine self-administration. Science 305: 1017-1019.

Vanderschuren LJMJ, Everitt BJ. 2005. Behavioral and neural mechanisms of compulsive drug seeking. Eur J Pharmacol 526: 77-88.

Ward SJ, Lack C, Morgan D, Roberts DCS. 2006. Discretetrials heroin self-administration produces sensitization to the reinforcing effects of cocaine in rats. Psychopharmacology 185: 150-159.

Wee S, Wang Z, Woolverton WL, Pulvirenti L, Koob GF 2007. Effect of aripiprazole, a partial dopamine D2 receptor agonist, on increased rate of methamphetamine self-administration in rats with prolonged session duration. Neuropsychopharmacology 32: 2238-2247.

Wee S, Mandyam CD, Lekic DM, Koob GF. 2008. $\alpha 1$-Noradrenergic system role in increased motivation for co- caine intake in rats with prolonged access. Eur Neuropsychopharmacol 18: 303-311.

Wee S, Orio L, Ghirmai S, Cashman JR, Koob GF. 2009. Inhibition of kappa opioid receptors attenuated increased cocaine intake in rats with extended access to cocaine. Psychopharmacology 205: 565-575.

Winstanley CA, Bachtell RK, Theobald DEH, Laali S, Green TA, Kumar A, Chakravarty S, Self DW, Nestler EJ. 2009. Increased impulsivity during withdrawal from cocaine self-administration: Role for DFosB in the orbitofrontal cortex. Cereb Cortex 19: 435-444.

Wise RA. 1973. Voluntary ethanol intake in rats following exposure to ethanol on various schedules. Psychopharmacologia 29: 203-210.

Wise RA. 1996. Addictive drugs and brain stimulation reward. Annu Rev Neurosci 19: 319-340.

Wolffgramm J. 1991. An ethopharmacological approach to the development of drug addiction. Neurosci Biobehav Rev 15: 515-519.

Wolffgramm J, Heyne A. 1991. Social behavior, dominance, and social deprivation of rats determine drug choice. Pharmacol Biochem Behav 38: 389-399.

Wolffgramm J, Heyne A. 1995. From controlled drug intake to loss of control: The irreversible development of drug addiction in the rat. Behav Brain Res 70: 77-94.

Zapata A, Minney VL, Shippenberg TS. 2010. Shift from goal-directed to habitual cocaine seeking after prolonged experience in rats. J Neurosci 30: 15457-15463.

Zhou W, Zhang F, Liu H, Tang S, Lai M, Zhu H, Kalivas PW. 2009. Effects of training and withdrawal periods on heroin seeking induced by conditioned cue in an animal of model of relapse. Psychopharmacology (Berl) 203: 677684 


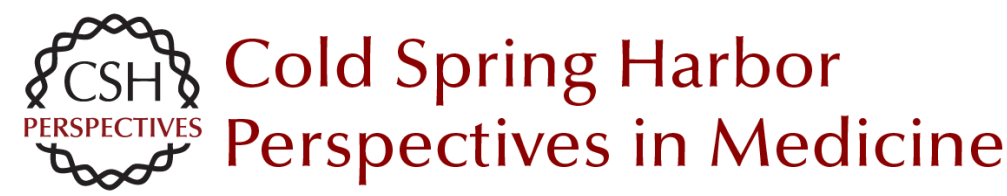

\section{Animal Studies of Addictive Behavior}

Louk J.M.J. Vanderschuren and Serge H. Ahmed

Cold Spring Harb Perspect Med 2013; doi: 10.1101/cshperspect.a011932 originally published online December 18, 2012

\section{Subject Collection Addiction}

Developments from Bulk Optogenetics to

Single-Cell Strategies to Dissect the Neural

Circuits that Underlie Aberrant Motivational States Jose Rodriguez-Romaguera, Vijay M.K. Namboodiri, Marcus L. Basiri, et al.

Consequences of Parental Opioid Exposure on Neurophysiology, Behavior, and Health in the Next Generations

Fair M. Vassoler and Mathieu E. Wimmer

Animal Models of the Behavioral Symptoms of Substance Use Disorders Louk J.M.J. Vanderschuren and Serge H. Ahmed

Translational Research in Nicotine Addiction Miranda L. Fisher, James R. Pauly, Brett Froeliger, et al.

Neonatal Opioid Withdrawal Syndrome (NOWS): A

Transgenerational Echo of the Opioid Crisis Andrew E. Weller, Richard C. Crist, Benjamin C. Reiner, et al.

Impairment of Synaptic Plasticity by Cannabis, $\Delta^{\mathbf{9}}$ -THC, and Synthetic Cannabinoids

Alexander F. Hoffman, Eun-Kyung Hwang and Carl R. Lupica

Drug-Evoked Synaptic Plasticity of Excitatory Transmission in the Ventral Tegmental Area Camilla Bellone, Michael Loureiro and Christian Lüscher

Opioid-Induced Molecular and Cellular Plasticity of Ventral Tegmental Area Dopamine Neurons Marie A. Doyle and Michelle S. Mazei-Robison
The Persistent Challenge of Developing Addiction

Pharmacotherapies

Sarah E. Swinford-Jackson, Charles P. O'Brien,

Paul J. Kenny, et al.

Opioid Modulation of the Gut-Brain Axis in Opioid-Associated Comorbidities

Li Zhang and Sabita Roy

Epigenetics of Drug Addiction

Andrew F. Stewart, Sasha L. Fulton and lan Maze

Genetic Vulnerability to Opioid Addiction

Brian Reed and Mary Jeanne Kreek

Glutamatergic Systems and Memory Mechanisms Underlying Opioid Addiction

Jasper A. Heinsbroek, Taco J. De Vries and Jamie Peters

Mechanisms of Nicotine Addiction

Marina R. Picciotto and Paul J. Kenny

Neural Substrates and Circuits of Drug Addiction Matthew W. Feltenstein, Ronald E. See and Rita A. Fuchs

The Role of the Central Amygdala in Alcohol Dependence

Marisa Roberto, Dean Kirson and Sophia Khom

For additional articles in this collection, see http://perspectivesinmedicine.cshlp.org/cgi/collection/ 